\title{
GAS ANALYSIS OF GEOTHERMAL FLUID INCLUSIONS: A NEW TECHNOLOGY FOR GEOTHERMAL EXPLORATION
}

\author{
(DOE grant number DE-F007-00ID13953)
}

\begin{abstract}
David I. Norman, Department of Earth and Environmental Science, New Mexico Tech, Socorro, NM 87801, USA, email: dnorman@nmt.edu
\end{abstract}

KEY WORDS: geothermal, gas, analysis, fluid, inclusion, exploration, monitoring, tracer, technology, stratigraphy, monitoring, plume, reservoir, magmatic, meteoric, air, saturated, water, condensation, condensate, boiling

\section{PROJECT BACKGROUND AND STATUS}

In 1994 ideas about geothermal gas chemistry were vague. Gaseous species are commonly the principal dissolved component in geothermal fluids, but the significance of the gas chemistry was mostly overlooked. Giggenbach presents the basic geothermal equilibrium gas chemistry (Giggenbach 1980) and calculates how boiling might affect $\mathrm{CO}_{2}-\mathrm{CH}_{4}-\mathrm{H}_{2}$ ratios in geothermal fluids (Giggenbach 1986). However, attempts at using gas equilibrium geothermometers for geothermal exploration largely failed.

I began collaboration with Joe Moore and Jeff Hulen, and later Sue Lutz at EGI, University of Utah, in 1994. We hypothesized that fluid inclusion gas analyses would complement their petrographic and fluid inclusion studies, and thus provide a comprehensive picture of geothermal system processes and evolution. That year I published a paper (Norman 1994), developing an idea brought forth by Giggenbach (1986), which shows that fluid inclusion gas analysis can identify a magmatic component in inclusion fluids. One of our goals was to apply this new tool to the study of active geothermal systems. Our collaboration has resulted in a number of publications that expand the science of geothermal gas chemistry and increase our understanding of geothermal processes and evolution (Moore 1995; Moore 1997; Lutz 1999; Adams 2000; Lutz 2002) (Moore 1997; Moore 1998; Moore 1998; Moore 1999; Moore 2000; Moore, Norman et al. 2001) (Norman 1994; Norman 1996; Norman 1997; Norman 1998; Norman 1999) (Norman 2001; Norman 2001; Norman 2002; Norman 2002)

In 1999 it was evident that with our increased understanding of geothermal gas chemistry that it could be a valuable tool for geothermal exploration. It was also apparent that geothermal gas chemistry had proven to be a valuable instrument for understanding evolution of geothermal systems, and that it order for Norman to spend more time on this work, funding was required. Therefore, funds were sought from the DOE university Geothermal Program.

\section{PROJECT OBJECTIVE}

The principal objective was to increase our knowledge of gaseous species in geothermal systems by fluid inclusion analysis in order to facilitate the use of gas analysis in geothermal exploration. 


\section{APPROACH and SUBOBJECTIVES}

1. Update the New Mexico Tech fluid inclusion gas analysis facility.

2. Add to the merger database of magmatic gases by measuring gases in magmatic glass inclusions.

3. Analyze the volatiles in Karaha fluid inclusions studied by Joe Moore.

4. Develop a technology base for the analysis of fluid inclusion organic compounds.

5. Develop methods of applying geothermal gas analysis to geothermal exploration using knowledge gained during the project

\section{RESEARCH RESULTS}

Sub-objectives 1-4 above were completed and reported on (Blamey Nigel J.F. 2001; Norman 2001; Norman 2001; Blamey 2002; Norman 2002; Norman 2002). Here I will report new methods for applying geothermal gas analysis to geothermal exploration, which is the main subject of the proposal.

The unique approach that was developed is to look at gas chemistry as a product of components from meteoric, crustal, and magmatic sources that are modified by geothermal processes of boiling, mixing, and condensation. Five assumptions are made: 1) gas chemistry of geothermal reservoir fluids is different from gas chemistry of non-thermal waters; 2) reservoir fluids commonly have additions of magmatic volatiles that have specific $\mathrm{He}-\mathrm{N}_{2}-\mathrm{Ar}$ ratios; 3) there are three sources of volatile compounds: magmas, the crust by wall rock reactions, and the atmosphere; 4) boiling, condensation, and fluid mixing processes result in systematic changes in gas chemistry; and 5) gas chemistry of past geothermal systems may also be determined by fluid inclusion gas analysis. The rationale for the interpretations we use is explained in detail elsewhere (Norman 2001; Blamey 2002; Norman 2002) and references therein. I will discuss examples of applying geothermal gas analysis to grass roots exploration at the Lightning Dock geothermal area, NM; to drill core chips at the Coso geothermal field; and to monitoring production at the Cerro Prieto field.

\section{Lightning Dock}

The Lightning Dock, Animas Valley, New Mexico geothermal area was discovered when a rancher found boiling water while drilling a shallow stock tank well (Elston, Deal et al. 1983). There are no surface manifestations of present or past geothermal activity in the Animas Valley. There is no geophysical low-resistivity anomaly. The only item to investigate is the waters in stock tank wells. Norman and Bernhart (1982) analyzed the gases, and water chemistry in the discovery well and 15 stock tank wells nearby (Fig. 1). The well temperatures are typical of shallow well waters; we did not know how to interpret the gas analyses at that time, and other geochemical analyses showed no identifiable geothermal input. AMAX Geothermal failed to find reservoir fluids in 8 boreholes drilled there in the late 70 's. 

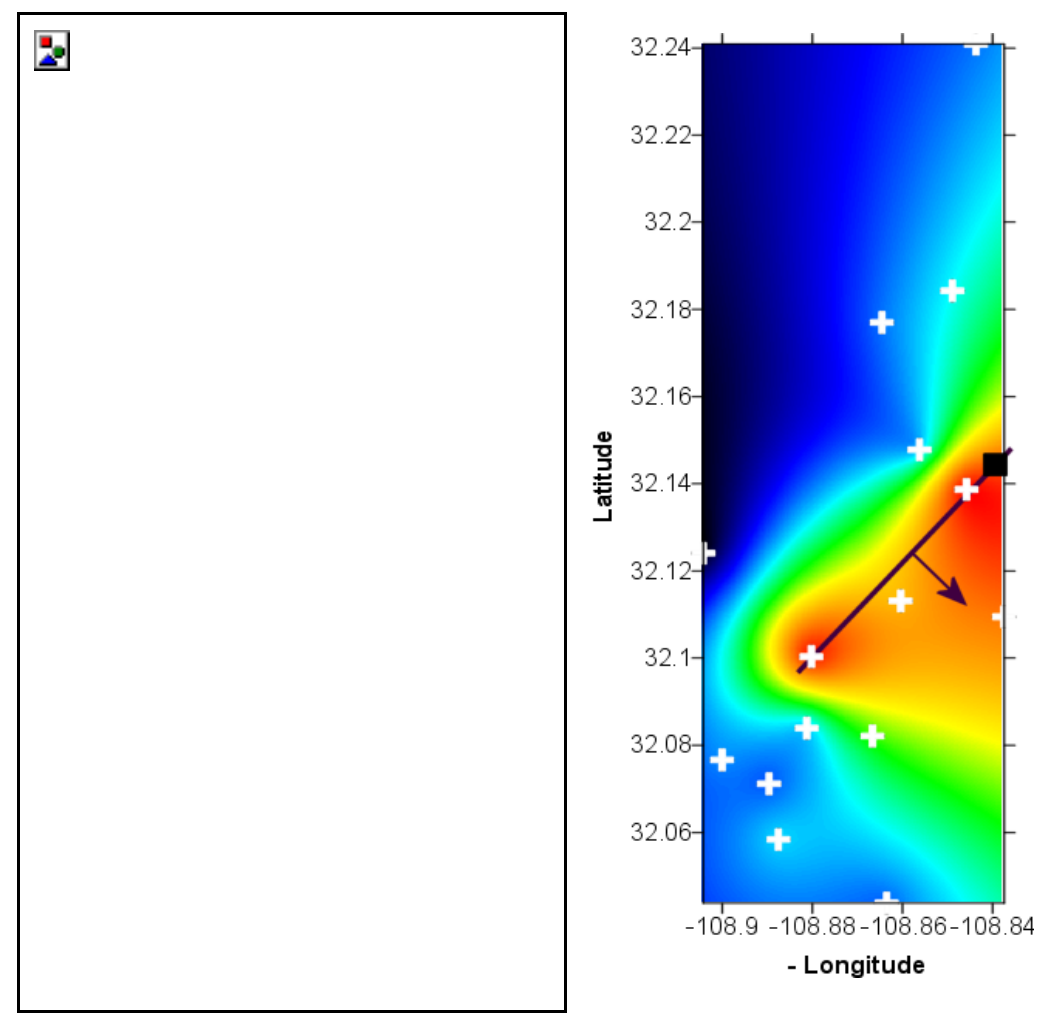

Figure 1 (Left) Location of the wells sampled in the Lightning Dock geothermal area. The number above each well is the measured well temperature. (Right) The right-hand figure is a Surfer ${ }^{\circledR}$ contour-image plot that shows the location of a vapor plume at Lightning Dock. The highest values of total gas are red and lowest values in dark blue. The white crosses are well locations; the black square is the discovery well. An inferred fault is shown with the dip direction. This newly developed method of using gas analyses to find condensed vapor shows a drilling target, whereas common geochemical methods used in geothermal exploration do not work at Lightning Dock.

Reevaluating our analyses now, it is apparent that the discovery well gas chemistry indicates boiling. The discovery well water has about $1 / 1000$ the $\mathrm{N}_{2}$ common in groundwater, which implies that the well fluid was degassed by subsurface boiling. The working assumption is that vapor generated by boiling Lightning Dock waters should exit the surface because there is no sign of vapor blockage and resulting hydrothermal eruptions. This flux of volatiles should condense some soluble species in shallow ground water. A gas mixing-condensation diagram (Norman 2002) was constructed

Figure 2 Analyses of Animas Valley wells

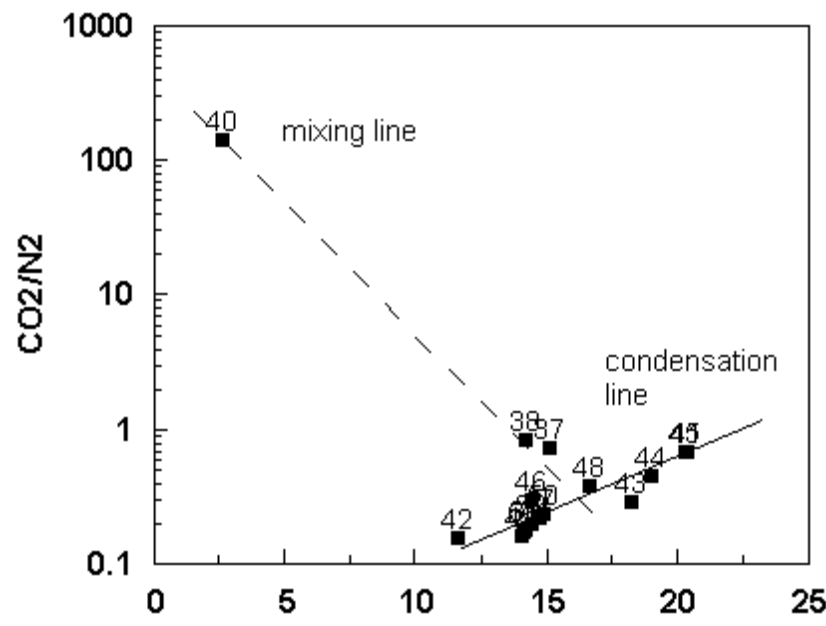
shown in Fig. 1 are plotted on a condensation diagram (Norman 2002). Numbers above data points are the well number. The condensation trend is labeled. A mixing line is constructed from the discovery well \#40 through wells \# 37 and 38. This diagram shows how gas data may be used to construct a fluid-mixing diagram. Mixing diagrams are a standard tool is interpreting geothermal fluids, however mixing diagrams to date use dissolved solids. Stock-tank well analyses fall on a condensation line (Norman 2002) hence; indicate a rising plume of volatiles modifies groundwater gas compositions. 
(Fig. 2) that clearly confirms condensation, and as well shows mixing between groundwater and the discovery well. The wells that exhibit fluid mixing are the two wells that are NNE and down the hydraulic gradient from the discovery well. Total gas amounts, save for the discovery well, were projected onto the condensation line, and the values kriged and contoured using Surfer ${ }^{\circledR}$ software (Fig. 1). This analysis shows the location of a gas plume, and suggests a structure trending NE-SW from the discovery site dipping to the SE. There are structures trending NE in the Lightning Dock district (Elston, Deal et al. 1983). However, the structure the gas data suggests does no3t show on maps because the Animas Valley is covered by thick gravel.

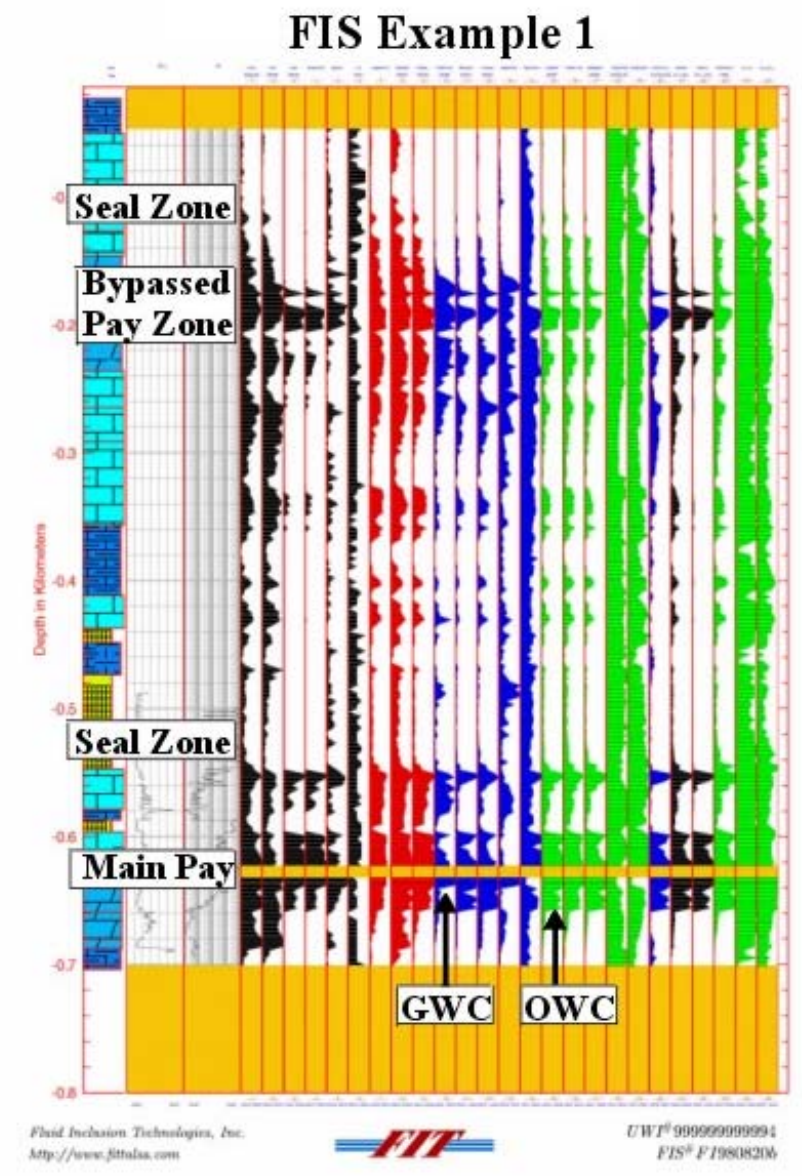

\section{FIS Analysis of a Michigan Basin Discovery Well, SW Ontario:}

The top of the targeted Silurian Reef occurs at $626 \mathrm{~m}$. FIS data identify the gas-oil contact at approximately $638 \mathrm{~m}$ and the oil-water contact at about $656 \mathrm{~m}$. This information can be used to optimize completion strategies.

A shallower, Devonian section at $176-194 \mathrm{~m}$ correlates with a zone of stained, porous dolomite. The interval was not logged and is typically drilled overbalanced. Hence, information on petroleum charge from standard wellsite techniques can be misleading. This section is interpreted to represent a bypassed pay interval in the area.

The shallow and deep anomalies are separated by what appear to be effective seal rocks.

\section{FIS Species Key:}

Black= inorganic volatile compounds Red = gas-range organic volatile species Blue $=$ water-soluble volatile compounds Green $=$ liquid-range organic volatile species

Figure 3. A "Fluid Inclusion Stratigraphy" example for a hydrocarbon well. Fluid inclusion analyses are performed on drill-chips taken at intervals of 30 or 60 feet and the relative heights of mass peaks corresponding to major species are plotted on mudlogs.

Several oil companies routinely use "Fluid Inclusion Stratigraphy" (FIS) whereby fluid inclusion volatiles in exploration-well drill-chips are analyzed at intervals of 10 or 20m (Hall 2002). Relative gas concentrations are plotted on well strip charts or mudlogs, and the stratigraphic intervals that act as seals and pay intervals for oil and methane are readily apparent (Fig. 3). This type of correlation should work for geothermal system exploration as well. Minor fractures penetrate far into the county rock from major structures in geothermal systems (Hickman, Barton et al. 1998). 

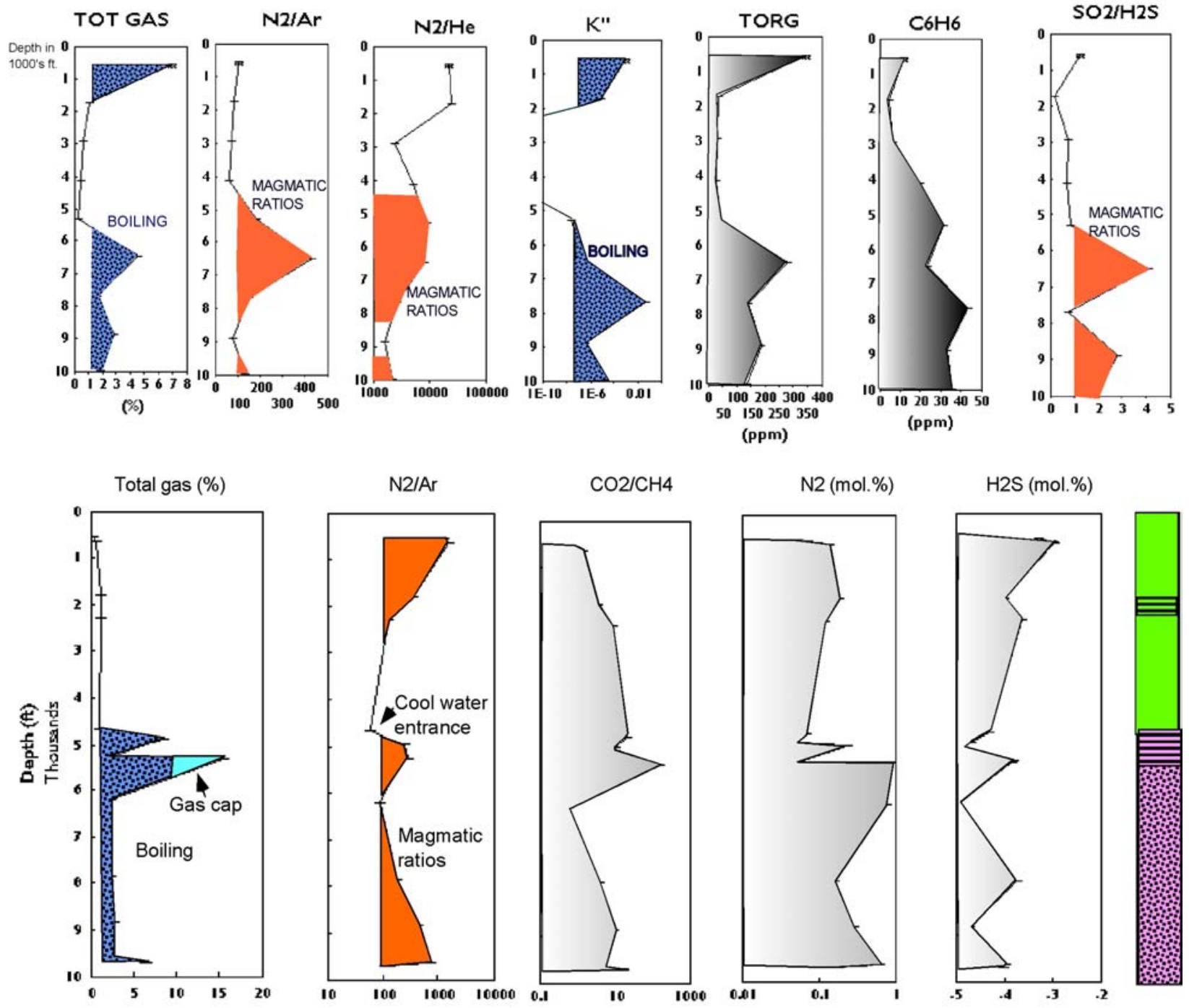

Figure 4 (Upper) Analysis of nine Coso well 83-16 drill-chip samples plotted verses depth in thousands of feet. TOT GAS is total gaseous species, $K$ " is the Fischer-Tropsch reaction coefficient, and TORG is the sum of $C_{2}-C_{7}$ organic species. Orange-filled areas indicate magmatic ratios; blue-filled areas on TOT GAS and $K$ " columns are values that indicate boiling. (Lower) Analyses of twelve vein samples from Coso well 68-6 are plotted verses depth. Filled areas in $\mathrm{N}_{2} / \mathrm{Ar}$ columns and total gas columns respectively indicate values for magmatic fluids and fluid boiling. See Fig. 5 for the explanation for the interpretive column at the right.

\section{Exploration Using Drill Chips}

Secondary inclusions form in the veins as the fractures heal within a few years at geothermal system temperatures. FIS has not been used in the geothermal industry because it was not known how to distinguish reservoir fluid inclusions from groundwater-filled fluid inclusions. Hydrocarbon-bearing fluids are easily distinguished by inclusions that contain organic compounds. 


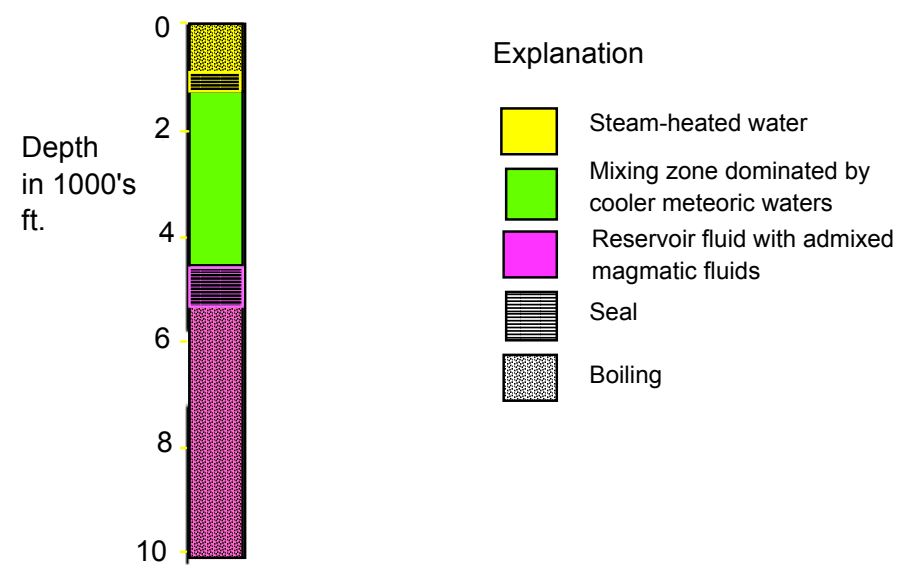

Figure 5. An interpretation of fluid types, fluid processes, and seal locations in Coso well 83-16, based on fluid inclusion gas analysis. The gas data is displayed in Figure 4. See text for an explanation of how the interpretations are made.

In order to test FIS for geothermal exploration, we analyzed drill chips from Coso well 83-16, which were selected at $1000 \mathrm{ft}$ intervals by Joseph Moore. Sequential crushes done by our CFS (crushfast-scan) method (Norman 1996) show that chips have a high density of homogeneous fluid inclusions. Analyses were averaged and plotted verses depth (Fig. 4), and interpreted (Figs 4 and 5). Fluid inclusion gas analyses done on vein minerals from drill hole 68-6 that we earlier analyzed (Adams 2000) were plotted for comparison (Fig. 4) in order to confirm that similar analyses are obtained from chips and vein minerals.

It is apparent looking at Fig. 4 that fluid inclusion analysis detects a change in gas chemistry at about $5500 \mathrm{ft}$, which is the top of the Coso production zone. Analyses for both wells show: 1) boiling fluids with a magmatic component below about $5000 \mathrm{ft}$; 2) a change in gas chemistry at 5000-6000 ft; 3) non-boiling, meteoric fluids immediately above $5000 \mathrm{ft}$; and 4) fluids with a magmatic component or boiling in waters $<1700$ '. Our interpretation of well 83-16 is that inclusions below $6000 \mathrm{ft}$ are samples of boiling reservoir waters (Fig. 5). Lack of boiling and meteoric $\mathrm{N}_{2} / \mathrm{Ar}$ ratios above $5000 \mathrm{ft}$ indicate that cooler meteoric waters dominate fluids there. The change in fluid chemistry and drop in fluid temperature at 5000-6000 ft. is best explained by a permeability seal. The indicated gas cap at about $5500 \mathrm{ft}$ in well $68-6$ also indicates a seal. Near-surface fluids have the characteristics of steam-heated waters with elevated $\mathrm{H}_{2} \mathrm{~S}$ and $\mathrm{C}_{6} \mathrm{H}_{6}$ and or a magmatic component. The difference in chemistry between surface waters and the immediately deeper fluid suggests a seal that must be penetrated by a few fractures transmitting steam from boiling reservoir fluids. The interpretation agrees well with the well $\log$ for bore hole 83-16 that shows the well cased to $6000 \mathrm{ft}$, a decrease in fluid temperatures at depths above $5500 \mathrm{ft}$, and an increase in temperatures at depths $<1700 \mathrm{ft}$. Our trial analyses roughly indicate the position of the Coso reservoir top. In actual practice, where analyses are done at more closely spaced intervals, we expect much better precision in determining reservoir boundaries. We expect that a greater density of analyses will also identify productive fractures as well.

Figure 6. Schematic cross section of a geothermal system like Coso showing conceptually how fluid inclusion stratigraphy interpretations, like those in Figs. 4 and 5, may be used to determine the location of a well site with respect to the center, margin, or outside of the geothermal system.

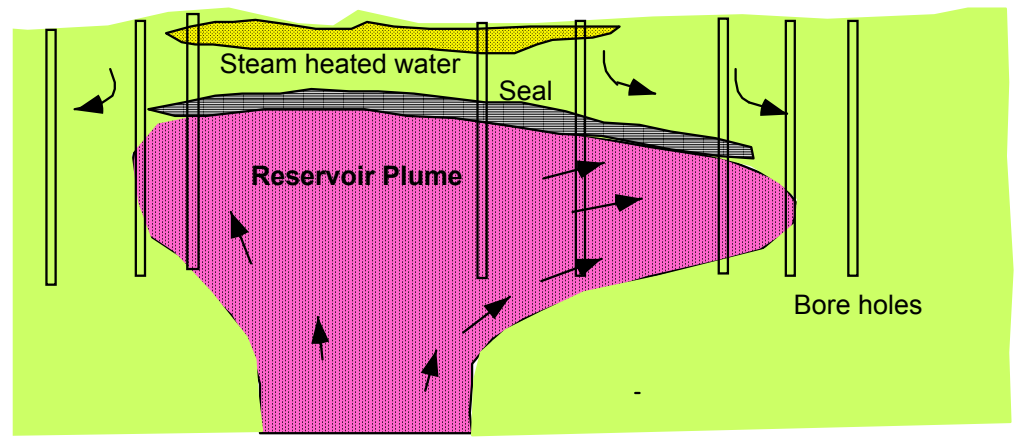



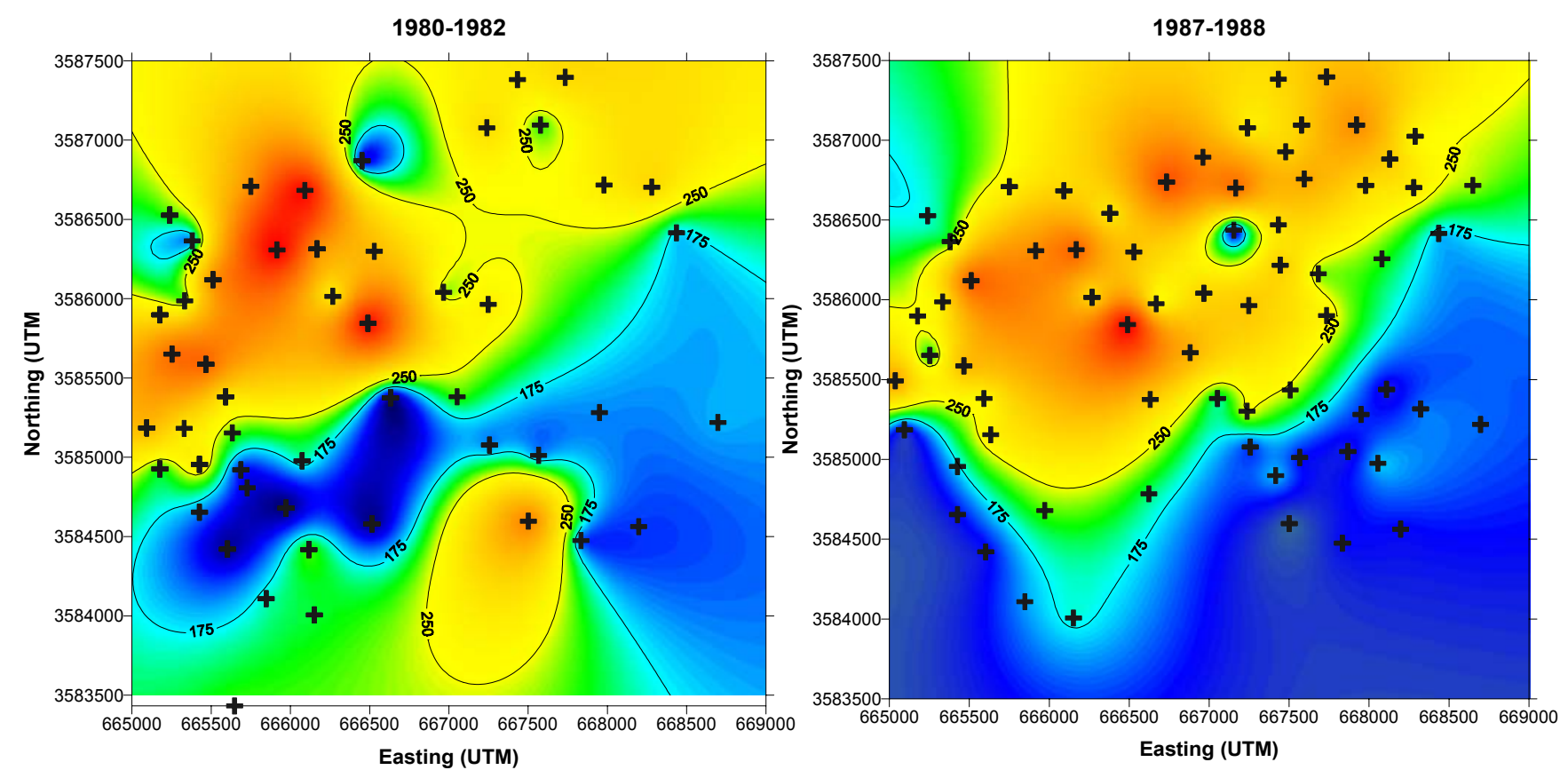

Figure 7. Contour plots of the Cerro Prieto geothermal plume produced by contouring $\mathrm{N}_{2} / \mathrm{Ar}+$ $\mathrm{CO}_{2} / \mathrm{N}_{2}$ ratios in gas analyses performed during 1980 to 1982 (left) and 1987-1988 (right). Values below 175 are waters with little or no meteoric component. Values $>250$ are fluids with a magmatic component. Gradations of blue to red show the respective proportions of meteoric and magmatic gaseous species. Black crosses locate wells that provided data for the map.

The preliminary analyses strongly indicate that FIS can be applied to geothermal systems. FIS will provide the same type of benefits it does in hydrocarbon exploration. It can be used with other well logging tools to maximize well production by showing productive and non-productive bore hole intervals. Commercial lab analyses are relatively inexpensive at $\$ 2,000$ to $\$ 6,000$ per bore hole (Hall 2002), the turnaround is in days, and data from commercial labs are formatted to be accepted by common strip log and mudlogging computer programs.

FIS analyses will have to be plotted differently than is done for the oil industry. Ratios of gaseous species that indicate fluid sources and fluid boiling will have to be added, and analyses of many organic compounds can be reduced. A valuable side benefit of FIS analyses is that analyses from a number of drill holes can be combined to provide a cross-sectional map of the reservoir (see Fig. 6).

\section{Producing Systems - Cerro Prieto}

A new way to monitor producing fields is introduced in (Norman 2002). The flow of geothermal fluids is mapped at the production level by use of gas chemistry obtained in routine field monitoring. Cerro Prieto gas analyses collected by Cathy Janik and Alfred Truesdell from 1977 to 1998 are used for the demonstration analyses (Fig. 7). Cerro Preito $\mathrm{CO}_{2} / \mathrm{N}_{2}$ and $\mathrm{N}_{2} / \mathrm{Ar}$ ratios correlate $\left(\mathrm{N}_{2} /\right.$ Ar ratios show contributions of magmatic volatiles), thus the sum of these ratios is 
used to tag magmatic-volatile-rich reservoir fluids.

The analyses show that reservoir fluid-flow changes with time, most probably as a result of a changing stress field change. The wells in the red areas on Fig 7 have the highest enthalpies (temperatures), and generally have sustained production for the period 1977-1988. During 19801982 there appears to be a NW trending control on magmatic-vaporrich fluids that coincides with a major NW-trending fault. The map for 19871988 shows the southern part of the field dominated by meteoric waters, and a shift in the magmatic-vapor-rich waters to a NE trend. Wire frame and shaded image diagrams (Fig. 8) more clearly show the linear features. A vector plot (Fig.9) shows the gradient from magmatic to meteoric fluid components. This should be in the direction of reservoir fluid flow, therefore should be useful in planning injection well locations.

At Cerro Prieto geophysics and mapping indicates these NE-trending structures (Lippmann 1997). The area of blue-colored meteoric gas-dominated waters that trend NE in the 1980-1982 map (Fig. 7, Left) corresponds to the "H" fault that dips to the SE (Lippmann 1997), which they conclude is an important control on recharge into the reservoir. Contours of Cerro

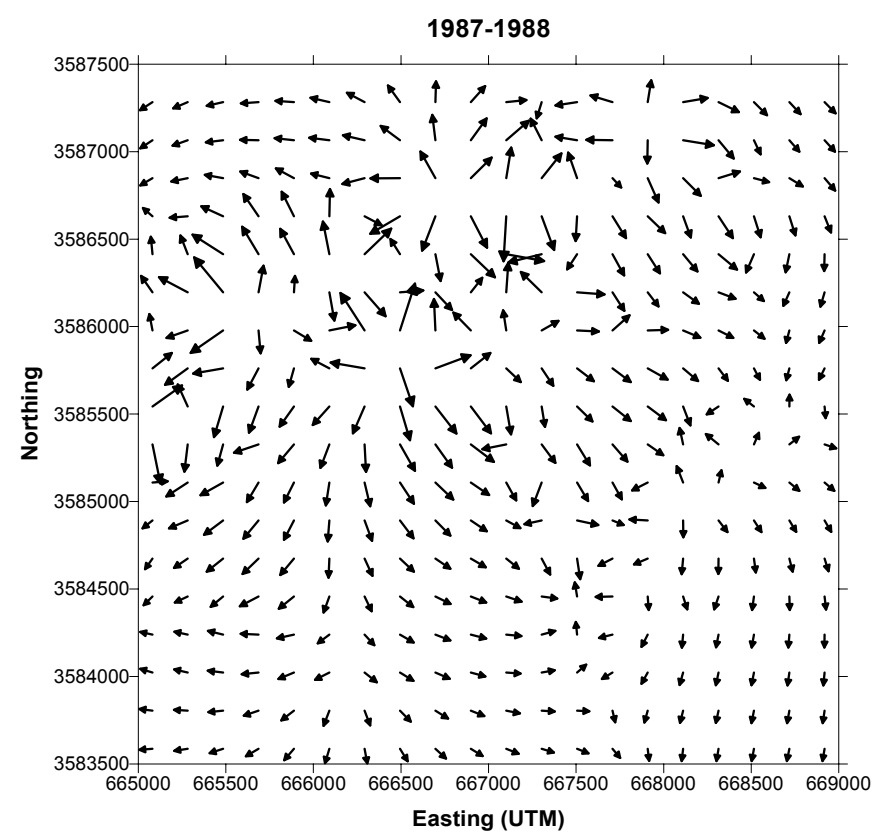

Prieto fluid salinity, enthalpy, and oxygen isotopic compositions (Lippmann 1997) also show a NE trend. Hence, NE-trending structures must be the main controls on Cerro Prieto fluids. Gas data alone (Fig. 8) appear to locate these structures.

Our examination of Cerro Prieto gas analyses indicates that the geothermal system structure is changing with time. Gas data Figure 9. Gas analyses shown in Fig. 7 are shown in a SURFER ${ }^{\circledR}$ vector plot. It shows the maximum rate of change from fluids with a magmatic gas component to fluids with meteoric and crustal gaseous species. Thus, the vectors should indicate the direction and magnitude of reservoir fluid flow. 
routinely measured in most geothermal fields; hence fluid-flow plots as presented here can be accomplished with little cost. Gas analytical data, therefore, are useful in developing management procedures for geothermal fields characterized by complicated, highly-fractured reservoirs where flow patterns may change with time.

\section{DETAILS}

Who Thinks the Research is Useful

1. Starting May 12, 2002 we are going to work with Lightning Dock Geothermal to do a detailed gas plume map in the same area shown in Fig. 2. The company plans to start a drilling program late summer 2002.

2. We will be analyzing chips on the new holes being drilled at Coso by the US Navy. We are planning with Caithness Energy on performing FIS analysis on chips from about 40 Coso boreholes. A commercial lab will make analyses; we will help interpreting the analyses.

3. Ridgeway Petroleum Corp. of Calgary, Canada who is drilling in New Mexico for $\mathrm{CO}_{2}-\mathrm{He}$ gas wishes to have drill chip analyses made during their drilling program.

\section{Collaborations}

Principal collaborations are with Joe Moore, Jeff Hulen, and Sue Lutz at EGI, University of Utah, and the companies mentioned above: Lightning Dock Geothermal, US Navy, Caithness Energy, and Ridgeway Petroleum Corp.

Papers Published: Eight papers published are: (Blamey Nigel J.F. 2001; Moore, Norman et al. 2001; Norman 2001; Norman 2001; Blamey 2002; Lutz 2002; Norman 2002; Norman 2002)

Students Supported: Nigel J.F. Blamey, Postdoc and Penny Oritz, undergraduate Research Assistant

\section{ADDENDUM}

This addendum to the DOE Final Report submitted in May 2002, details how the results of grant DE-F007-00ID13953 were used by industry and for continued research. Two grants were awarded from information generated by the DOE grant and another grant application to DOE is pending. Knowledge developed by this grant to is being used to assess geothermal systems, and to develop new exploration and assessment methods. The addendum outline will follow the report and address Lightningdock geothermal system; analysis of fluid inclusions in well bore cuttings, and application published knowledge to producing geothermal fields. 


\section{Lightningdock:}

The idea that the there should be a detectable gas flux in Lightningdock basin sediments based on the amount of $\mathrm{N}_{2}$ in well waters was tested. Over 400 carbon dioxide flux measurements were made on the Lightningdock Field. They show that there is anomalous gas flux directly over an inferred fault, and that the data suggests locations of hidden faults (McLin et al., 2004). At present data on other gas species than $\mathrm{CO}_{2}$ is being collected. This work was funded in part by the DOE grant to Lightningdock Geothermal.

\section{Exploration Using Drill Chips}

The ideas presented above were used to two obtain two grants:

1. Fluid Inclusion Stratigraphy: A New, Inexpensive Method for Geothermal Reservoir Assessment; CALIFORNIA ENERGY COMMISSION - 3 years $(\$ 724,911)$, May, 2003 sponsored by Coso Operating Company Ltd.

2. Thermal and Chemical History of the Eastern Side of the Coso Geothermal Field, US Navy, - 2 years $(\$ 105,241)$ starting date July 1,2002

Pending Grant: Geochemical Enhancement Of EGS Reservoirs: An Integrated Field And Geochemical Approach, DOE with EGI-U of Utah 3 years $(\mathbf{\$ 7 5 0 , 0 0 0 )}$

The CEC grant is to prove the ideas of how fluid inclusion gas analysis of bore hole cuttings can be used in geothermal exploration and bore hole assessment. Analyses are perfomed by a private company, Fluid Inclusion Technologies, who analyzes drill chips for the oil industry.

Preliminary findings (Dilley, Norman, and Berard; 2004) indicate that fluid inclusion analysis of bore hole chips can easily differentiate production from non-productive wells, identify fractures, and identify fluid source. Similar analyses of cuttings done on chips from new Coso wells drilled by the US Navy indicate the wells are sites of recharge (Norman et al. 2003)

\section{Applications to Producing Systems}

Moore, Norman, and Allis (2002) show that gas ratios define the center of the Karaha-Telaga Bodas geothermal field. Coso gas analyses identify propene (Jess McCullock, personal communication) after we reported them in fluid inclusions (Norman et al., 2003). At present Coso geochemists are applying the methodology described above, and in Norman (2002), for identifying a plume of magmatic gases. They will use propane/propene ratios (Norman et al., 2004) in production fluids to map fluid sources.

ADDENDUM REFERENCES - those identified with * acknowledge funding by DOE grant number DE-F007-00ID13953

McLin, Kristie, David Norman, and Philip Kyle, (2004) Mapping Faults in the Lightning Dock 
Known Geothermal Area, Animas Valley, New Mexico Using Soil Co ${ }_{2}$ Flux

Measurements: Twenty-Ninth Workshop on Geothermal Reservoir Engineering Stanford University, Stanford, California, Jan. 26-28, 2003

Moore, J. N., D. I. Norman \& R. G. Allis, (2002) Geochemical Evolution of the Vapordominated Regime at Karaha-Telaga Bodas, Indonesia: Insights from Fluid Inclusion Gas Compositions, (in press), Presented at the $24^{\text {th }}$ New Zealand Geothermal Workshop, Auckland, November, 2002

Norman, DI and Joseph N. Moore, Lorie Dilley', and Brian Berard (2004), Geothermal Fluid Propene and Propane: Indicators of Fluid Source: Twenty-Ninth Workshop on Geothermal Reservoir Engineering Stanford University, Stanford, California, Jan. 26-28, 2003

*Norman, David I., Moore, J.N., (2003), Organic Species in Geothermal Waters in Light of Fluid Inclusion Gas Analyses; Twenty-Eighth Workshop on Geothermal Reservoir Engineering Stanford University, Stanford, California, Jan. 28-30, 2003, p. 96-103.

Norman, DI, Moore, JN, Kurilovitch, L. (2003), Thermal and Chemical History of the Eastern Side of the Coso Geothermal System, Proceedings of the US Navy PTO Special Meeting, UC Davis, June 4-5, 2003

*Norman, D. I., Nigel Blamey, Kurilovitch, Lynne (2002a). New Applications of Geothermal Gas Analysis to Exploration. Geothermal Resources Council Transactions: v. 26, p. 345353.

REFERENCES - those identified with * acknowledge funding by DOE grant number DEF007-00ID13953

Adams, M. C., Moore, J. N., Bjornstad, Norman, D.I (2000). "Geologic history of the Coso geothermal system." Transactions, Geothermal Resources Council 24: 205-209.

*Blamey, N., Norman, David I. (2002). New Interpretations of Geothermal Fluid Inclusion Volatiles: $\mathrm{Ar} / \mathrm{He}$ and N2/Ar ratios - A Better Indicator of Magmatic Volatiles, and Equilibrium Gas Geothermometry. PROCEEDINGS, Twenty-Seventh Workshop on Geothermal Reservoir Engineering Stanford University, Stanford, California.

*Blamey Nigel J.F., D. I. N. (2001). " Fluid Inclusion Evidence for a Supercritical Magmatic Fluid, Modified by Wall-rock Interaction and Mixing with Meteoric Waters." PROCEEDINGS, Twenty-Sixth Workshop on Geothermal Reservoir Engineering Stanford, California, January 29-31, 2001: 243-251.

Elston, W. E., E. G. Deal, et al. (1983). Geology and geothermal waters of Lightning Dock region, Animas Valley and Pyramid Mountains, Hidalgo County, New Mexico, New Mexico Bureau of Mines and Mineral Resources, United States.

Giggenbach, W. F. (1986). The use of gas chemistry in delineating the origin of fluids discharges over the Taupo Volcanic Zone: A review. International Volcanological Congress, Hamilton, New Zealand,.

Giggenbach, W. F. T. G. g. e. (1980). "Geothermal gas equilibria." Geochimica et 
Cosmochimica Acta 44(12): 2021-2032.

Hall, D. (2002). Fluid Inclusion Technologies, Inc., http://www.fittulsa.com/

Hickman, S. H., C. A. Barton, et al. (1998). In situ stress and fracture permeability along the Stillwater fault zone, Dixie Valley, Nevada. 36 th U. S. Rock mechanics symposium. New York, NY, Pergamon, Oxford-New York, International: 414.

Lippmann, M. J., Alfred H. Truesdell, Héctor Gutiérrez Puente (1997). Fluid Recharge at the Cerro Prieto Geothermal Field, U.S. Department of Energy

Geothermal Energy Technical Site.

Lutz, S. J., Joseph N. Moore, Nigel J.F. Blamey, David I. Norman (2002). "Fluid-Inclusion Gas Chemistry of the Dixie Valley (NV) Geothermal System." PROCEEDINGS, TwentySeventh Workshop on Geothermal Reservoir Engineering Stanford University (in press).

Lutz, S. J., Moore, J. N., Adams, M. C., Norman, D. I., 1999, (1999). "Tracing fluid sources in the Coso geothermal system using fluid-inclusion gas chemistry." 24th Workshop on Geothermal Reservoir Engineering, Stanford University: 188-195.

Moore, J., Norman, D., Hulen, J. (1995). "Evolution of The Geysers: Data from fluid inclusion microthermometry and gas chemistry." 17th New Zealand Geothermal Workshop: 77-82.

Moore, J. N., Anderson, A. J., Adams, M. C., Aines, R. D., Norman, D. I., Walters, M. A. (1998). "The fluid inclusion and mineralogic record of the transition from liquid- to vapor-dominated conditions in The Geysers geothermal system, California." Twentythird Workshop on Geothermal Reservoir Engineering, Stanford University: 211-218.

Moore, J. N., D. I. Norman, et al. (2001). "Fluid inclusion gas compositions from an active magmatic hydrothermal system: A case study of The Geysers geothermal field, USA." Chemical Geology 173: 3-30.

Moore, J. N., Norman, D. I., Kennedy, B. M., Adams, M. C. (1997). "Origin and chemical evolution of The Geysers, California, hydrothermal fluids: Implications from fluid inclusion gas compositions: Geothermal Resources Council Annual Meeting, 1997." 635641.

Moore, J. N., Norman, D. I., Kennedy, B. M., Adams, M. C. (1999). "The thermal and chemical evolution of the hydrothermal minerals in Awibengkok 1-2, Awibengkok geothermal field, Indonesia." Geothermal Resources Council Transactions: 25-29.

Moore, J. N., Powell, T. S., Bruton, C. J., Norman, D. I., Heizler, M. T., 1998, (1998). "Thermal and chemical evolution of the Tiwi geothermal system, Philippines." Proceedings of the 9th International Conference on Water-Rock Interaction, Taupo, N.Z.: 671-674.

Moore, J. N., Powell, T. S., Heizler, M. T., Norman, D. I (2000). "Mineralization and hydrothermal history of the Tiwi geothermal system, Philippines." Economic Geology 95(1001-1023).

Moore, J. N., Powell, T. S., Norman, D.I., Johnson, G. (1997). "Hydrothermal alteration and fluid- inclusion systematics of the reservoir rocks in Matalibong-25, Tiwi, Philippines: Twenty Second Workshop on Geothermal Reservoir Engineering, Stanford University." 447-456.

Norman, D. I., Bernhart, C (1982). Assessment of geothermal reservoirs by analysis of gases in thermal waters, New Mexico Energy Institute, EMI-2-68-2305.

Norman, D. I., Chomiak, B. A., Moore, J. N., (1998). Approaching equilibrium from the hot and cold sides in the pyrite-pyrrhotite-magnetite-H2S-CO2-CH4 system in light of fluid inclusion gas analysis. Proceedings of the 9th International Conference on Water-Rock Interaction, Taupo, N.Z., Taupo, New Zealand. 
Norman, D. I., Moore, J. N.. (1994). "Fluid source tracing via fluid inclusion gas analysis in an evolving magmatic system: The Geysers California (abs.)." VII International Symposium on the Observation of the Continental Crust Through Drilling, Santa Fe, N.M., April 2530, 1994.

Norman, D. I., Moore, J.N (1999). Methane and Excess N2 and Ar in geothermal fluid inclusions. Proceedings: Twenty-fourth Workshop of Geothermal Reservoir Engineering, Stanford University, Stanford, California.

Norman, D. I., Moore, J.N., Musgrave J. (1997). Gaseous species as tracers in geothermal systems. Proceedings: Twenty-second Workshop of Geothermal Reservoir Engineering, Stanford University, Stanford, California.

Norman, D. I., Moore, J.N., Yonaka, B., Musgrave, J (1996). Gaseous species in fluid inclusions: A tracer of fluids and an indicator of fluid processes. Proceedings: Twenty-first Workshop of Geothermal Reservoir Engineering, Stanford University, Stanford, California.

Norman, D. I., Musgrave, J.A. (1994). " $\mathrm{N}_{2}-\mathrm{Ar}-\mathrm{He}$ compositons in fluid inclusions: Indicators of fluid source." Geochimica et Cosmochimica Acta 58: 1119-1131.

Norman, D. I., Nigel Blamey (2002). "New Applications of Geothermal Gas Analysis to Exploration." Geothermal Resources Council Transactions (in press).

*Norman, D. I., Nigel Blamey, Joseph N. Moore (2002). Interpreting Geothermal Processes and Fluid Sources from Fluid Inclusion Organic Compounds and CO2/N2 Ratios. PROCEEDINGS, Twenty-Seventh Workshop on Geothermal Reservoir Engineering Stanford University, Stanford, California.

*Norman, D. I., Nigel J.F.Blamey, Joseph N. Moore (2001). Overabundance of Gaseous Species and the Source of Organic Compounds in Geothermal Fluids. PROCEEDINGS, TwentySixth Workshop on Geothermal Reservoir Engineering, Stanford University, Stanford, California.

Norman, D. I. and Blamey, Nigel J.F., (2001). "Quantitative Analysis of Fluid Inclusion Volatiles with a Two Mass Spectrometer System." Proceedings of ECROFI XVI, Oporto, Portugal, April, 2001. 